\title{
Intelligent controlled UPQC for power quality improvement of grid supply connected with non-linear load
}

\author{
Sudhir Sharma ${ }^{1}$, Shivani Mehta ${ }^{2}$, Chintu Rza ${ }^{3}$ and Mukesh ${ }^{4}$ \\ ${ }^{\text {I}}$ H.O.D. at Department of Electrical Engineering, DAV institute of Engg. \& Tech., Jalandhar, INDIA \\ Email: sudhir.abc@gmail.com) \\ ${ }^{2}$ (Assistant Professor at Department of Electrical Engineering, DAV institute of Engg. \& Tech., Jalandhar, \\ INDIA Email: shivanimehta7@gmail.com) \\ ${ }^{3}$ (Assistant Professor at Department of Electrical Engineering, DAV institute of Engg. \& Tech., Jalandhar, \\ INDIA Email: chinturza78@gmail.com) \\ ${ }^{4}$ (M.Tech student at Department of Electrical Engineering, DAV institute of Engg. \& Tech., Jalandhar, INDIA \\ Email: mukesh.daviet09@gmail.com)
}

\begin{abstract}
The issue of power quality has gained popularity in the recent years because of the widespread use of power electronic devices, larger inter-connected load networks and widespread use of non-conventional source of electrical energy like wind power, solar power etc. in the power system. The deterioration of the power quality may cause unwanted losses in the system, poor efficiency, interference with the communication lines, and faulty operation of devices and even may cause fault in some devices. In this paper the power quality issue because of the presence of non-linear load connected to the electric grid is discussed and an effort has been made to improve the power quality of the system using a device known as Unified Power Quality Conditioner (UPQC). For this the intelligent controlled UPQC is developed and used with the Grid supply connected to the Non-linear load and percentage Total Harmonic Distortion (THD) of voltage and current waveforms is measured in order to determine the power quality at different locations in the system. The intelligent controlled method has been found to have superior performance over the conventional Proportional Integral (PI) controlled UPQC. The results obtained verified using MATLAB/SIMULINK software.
\end{abstract}

Keywords - Unified Power Quality Conditioner (UPQC), Proportional Integral controller (PI controller), Active power filters (APF), Insulated gate bipolar transistor (IGBT), Artificial neural network (ANN), Pulse width modulation (PWM), Phase locked loop (PLL)

\section{INTRODUCTION}

With the increasing advancement in the field of electronics and the introduction of electronic devices into the power system the concept of Power quality has become very popular worldwide. These electronic devices are very sensitive to the variations in the voltage and current like harmonics, flickering, sags and swells etc. thus the quality of power is needed to be maintained. Although these electronic devices are also one of the reasons for the reduction in the power quality of the system as these electronic devices behaves as nonlinear load and cause unwanted distortions in the power system. In this paper the device known as UPQC is used for the power quality of the system consisting of a grid supply connected to the nonlinear load. The control system of the UPQC is the major factor which decides the performance of the UPQC and its effectiveness in the system.

The control system plays the important role of determining the error signal from the reference signal and the measured signal. There are different controlling strategies present in the today's time which are well discussed in [1], these includes PI, PID, fuzzy-logic, sliding-mode, predictive, unified constant frequency (UFC) controllers etc., are discussed in [2]-[4]. The PID controller requires very accurate mathematical modelling similar to the conventional PI controller, thus it fails to perform satisfactorily under parameter variation of the nonlinearity load disturbance, etc. The new unconventional controllers are being developed now a days which have improved performance and have replaced the conventional controllers. One such controller (intelligent controller) has been developed in this paper using the Artificial Neural Network (ANN) which has the ability to learn from the changes and adapt them to make decisions on their own to improve the performance of UPQC. A three feedforward type ANN based controller is developed to control the series inverter of the intelligent controlled UPQC. Various simulation results are presented in the paper which compare the performance of intelligent controller with the conventional PI controller. The section II of this system describes the configuration of the UPQC, while Sections III \& IV discuss the PI and Intelligent 
controller designs respectively and section $\mathrm{V}$ presents the simulation results of the system.

\section{CONFIGURATION OF UPQC}

In the UPQC two voltage source inverters are connected back to back with a common DC capacitor bus which provides both the series as well as shunt compensation at the same time. These two inverters, which are voltage source inverters are connected to a common DC link in between them as shown in the figure below. The two inverters are also called series and shunt inverters. The Distortions in the load current are compensated by the Shunt inverter and the smoothening of voltage is done by series inverter, both these compensations are provided simultaneously. In the shunt inverter the current is delivered to the load which is equal to the set reference value as decided by the controlling technique used in the UPQC, additionally the DC bus link is also maintained at a constant voltage by the shunt controller for improving the performance of the UPQC up to the desired level [5].

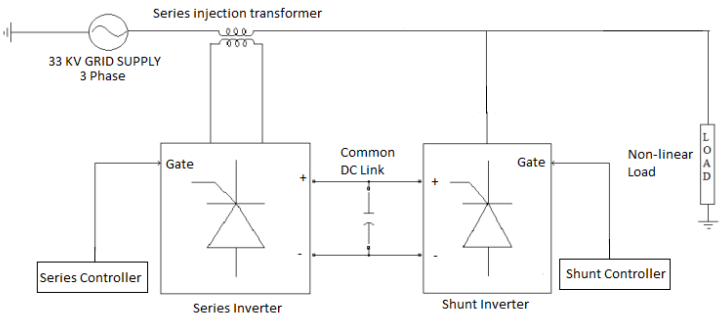

Fig. 1: Block diagram of UPQC

The UPQC performance IS greatly dependent upon the controlling technique used to derive the reference signals in it. The more accurate and quick derivation of reference signals results into the improved performance of UPQC. In the conventional PI controlled UPQC the difference between the DC bus voltage and the reference voltage is fed to the PI controller then to Pulse Width Modulation (PWM) for the generation of gating signals for the inverter.

\section{DESIGNING OF PI CONTROLLER}

In the series controller of the PI controlled UPQC the balancing of voltage at the supply side is achieved by injection of series inverter voltage, hence improving the voltage being delivered to load. For synchronization of supply the phase locked loop (PLL) is used. A suitable gain is provided to the sensed voltage and this gain is multiplied with the supply voltage before being injected into the PLL. PLL is fed with three phase distorted supply and then PLL generates an angle ranging from 0 to $2 \pi$ and when the zero crossing is sensed in positive sequence phase it gets synchronized. Now unit vectors are multiplied with the weighted gain from PLL with sin $\omega t, \sin (\omega t-2 \pi / 3)$ and $\sin (\omega t+2 \pi / 3)$. Now reference voltage is multiplied with these unit vectors to get the reference source voltage $\mathrm{V} * \mathrm{~S}$. Now the voltage vectors are compared with the line voltage VL. Then the error is generated VSr which is being fed to the PI controller. Further the O/P of PI controller is given to PWM which compares the error signal with the carrier signal and hence generates the desired pulses which are being supplied to the gate of the converter. Now these pulses will trigger the series converter during the period of voltage fluctuation hence will compensate the voltage to the desired value. In the series controlling is achieved by generating the voltage being injected and injecting it into the line voltage to achieve the sinusoidal voltage, which is free from harmonics and distortions [6]. The basic operation of the series inverter of the UPQC can be explained using the equation given below.

$$
\operatorname{VSr}(\omega \mathrm{t})=\mathrm{V} * \mathrm{~S}(\omega \mathrm{t})-\mathrm{VL}(\omega \mathrm{t})
$$

Where VSr $(\omega \mathrm{t}), \mathrm{V} * \mathrm{~S}(\omega \mathrm{t})$, and VL $(\omega \mathrm{t})$ represent the injected series inverter voltage, reference source voltage, and the voltage of the line, respectively. In the case of variation in the voltage from the prescribed value the series inverter injects the required voltage into the line and hence compensating the voltage level to the desired value.

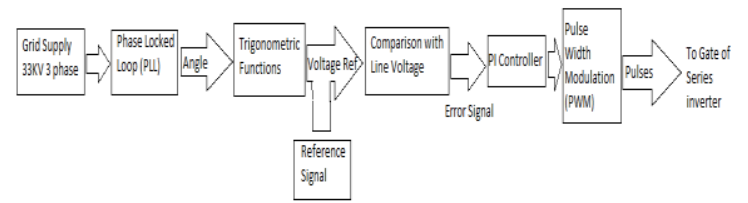

Fig. 2: Block diagram of Series control of PI controlled UPQC

The shunt controller is controlled by the theory called instantaneous reactive power theory (pq). The reference signals which are to be supplied to the shunt converter are generated by this theory. Here the current and voltage from the source side i.e. Vsabc and Isabc are injected into the controller where $\mathrm{p} \& \mathrm{q}$ are generated. Further one $\mathrm{p} \& \mathrm{q}$ signal is passed through the low pass filter and the other through the normal line and then the signals from the filters I*S and normal line IL are compared and error signal ISh is generated. This error signal ISh generated is fed into the PI controller. The $\mathrm{p}$ and $\mathrm{q}$ acts as direct and quadrature components of the signal as they are 90 degree apart. Then error signal generated by comparing Vdc and Vdcref is fed to the PI controller and then is added to the $\mathrm{p}$ component coming from the pq conversion block. Now d-q components are given to the multiplexer with a constant signal ' 0 ' being added with them so as to convert the signal into d-q-o signal. Now the d-q-o signal is injected in the inverse park transformation 
block with angle coming from PLL for synchronization and by applying inverse Park's transformation we get the signal in a-b-c frame as explained earlier in SRF theory. In PLL the phase angle was detected from the Vsabc. Then a-b-c components are evolved and are fed to the PWM block where it is compared with the carrier signal and relevant pulses are generated which are to be delivered to the shunt converter. Now the shunt inverter will inject the current into the line so as to compensate the reactive power demand also during the harmonic period it stabilizes the circuit current and restores the sinusoidal waveform of the circuit current. In the shunt inverter the current equal to the set value as determined by the controlling technique used in the UPQC is delivered to the circuit. Also the shunt inverter performs the important function to maintain the DC bus at the set reference value so that the desired performance can be achieved from the UPQC. The shunt inverter should inject the current into the circuit as determined by the equation given below.

$$
\operatorname{ISh}(\omega \mathrm{t})=\mathrm{I} * \mathrm{~S}(\omega \mathrm{t})-\mathrm{IL}(\omega \mathrm{t})
$$

Where ISh $(\omega t), \quad I * S(\omega t)$, and IL $(\omega t)$ represent the shunt inverter current, reference source current, and line current, respectively.

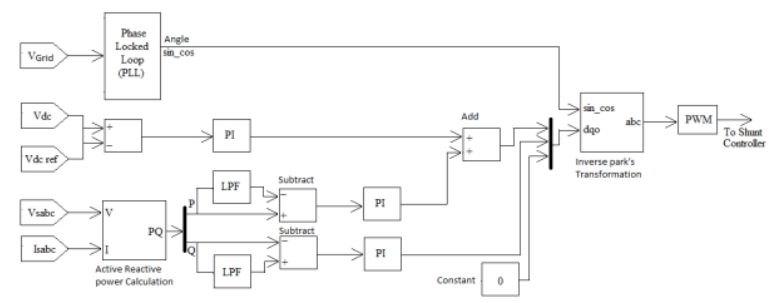

Fig. 3: Shunt control of PI controlled UPQC

\section{DESIGNING OF INTELLIGENT CONTROLLER}

In the series control the algorithm is developed by deriving voltage vectors from the supply. For synchronization of supply the PLL is used. A suitable is multiplied with the sensed voltage before being injected into the PLL. PLL is fed with three phase supply and then PLL generates an angle ranging from 0 to $2 \pi$ and when the zero crossing is sensed in positive sequence phase it gets synchronized. Now unit vectors are multiplied with the weighted gain from PLL with $\sin \omega t, \sin (\omega t-2 \pi / 3)$ and $\sin (\omega t+2 \pi / 3)$. Further the reference signal $(220 *$ sqrt2) is multiplied with these vectors to get the reference voltage vectors. Now the voltage vectors are compared with the line voltage, which is fed to the gates of the various IGBT's via relay and Data type conversion block. The series voltage is injected through the three series transformers connected one in each phase and RL low pass filter is used in each phase to remove the high frequency switching ripples from the injected voltage.

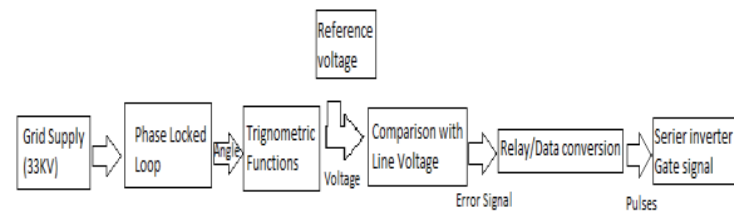

Fig. 4: Series control of intelligent controlled UPQC

In the Shunt control the comparison is made between the DC bus voltage and the reference DC voltage $(400 \mathrm{~V})$. The error signal obtained is given to the ANN. The output of the ANN Controller is added with the output of Active power estimation block via 2 nd order filter and a suitable gain which is multiplies by the voltage vectors Vaalpha, Vbalpha and Vcalpha respectively and the output of which is then divided by the sum of square of voltages from (Valpha and Vbeta) to get the value of three phase reference current, these values of reference currents are then compared with line current to get the error signal which is fed to the relay and Data type conversion block to feed the gates of various IGBT's of Shunt APF. The current compensation is injected directly to the three phase lines without any transformer as shown in the figure and RL low pass filter is connected in each phase to remove the high frequency switching ripples.

The ANN consisting of the interconnected artificial neurons which have the ability to learn and adapt. These intelligent networks are characterized in the manner they are trained, their communication with the environment and the way in which they use their information and their ability to use it [7],[8]. The Neural network is made with three layers, the input layer, the second layer which is also called as hidden layer and the output layer as shown in figure.

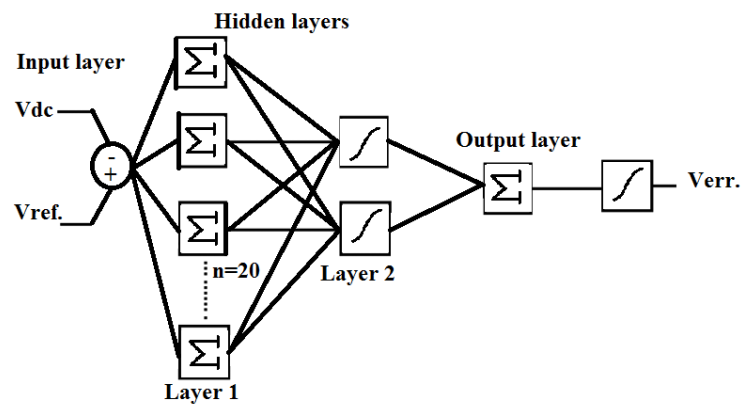

Fig. 5: Network topology for ANN 


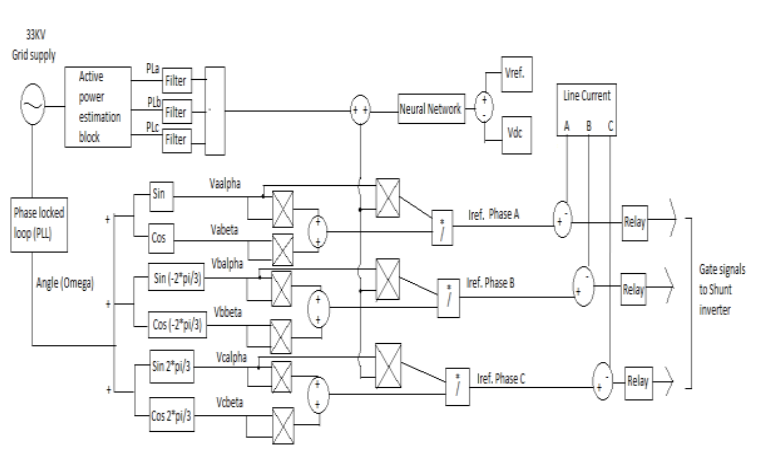

Fig. 6: Shunt control of intelligent controlled UPQC'

\section{SIMULATION RESULTS}

The MATLAB/SIMULINK model consists of a grid supply of $33 \mathrm{KV}$, the double circuit transmission lines, a step down transformer of $33 \mathrm{KV} / 690 \mathrm{~V}$ (630KVA) and a non-linear load consisting of a RLC series load on Diodes having active power of $10 \mathrm{e} 3$ watts, Inductive reactive power $=100$ VAR (Positive) and Capacitive reactive power $=100$ VAR (Negative) is as shown in figure 8. Percentage THD analysis is done on five different locations in the power system i.e.

1. At GRID side

2. At Point of common coupling (PCC)

3. At Transformer (T/F) side

4. At UPQC

5. At extreme Non-linear load side

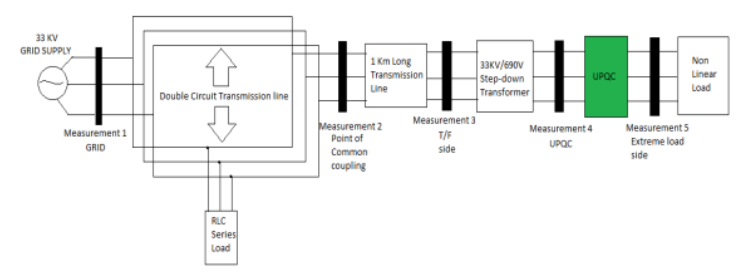

Fig 7: Block diagram of Simulation model used for THD analysis of the powers system

The results obtained from the THD analysis of the system without UPQC, with conventional UPQC and with intelligent controlled UPQC at different locations in the power system are as shown in the Table 1.

TABLE 1: Results of \%THD at various locations

\begin{tabular}{|c|c|c|c|c|c|c|}
\hline \multirow[t]{2}{*}{$\begin{array}{l}\text { Locat } \\
\text { ion of } \\
\text { meas } \\
\text { urem } \\
\text { ent of } \\
\% \\
\end{array}$} & \multicolumn{2}{|c|}{$\begin{array}{l}\text { \% THD } \\
\text { without } \\
\text { UPQC of } \\
\text { three } \\
\text { phases }\end{array}$} & \multicolumn{2}{|c|}{$\begin{array}{l}\text { \% THD with } \\
\text { conventiona } \\
1 \text { UPQC of } \\
\text { three phases }\end{array}$} & \multicolumn{2}{|c|}{$\begin{array}{c}\% \mathrm{THD} \text { of } \\
\text { intelligent } \\
\text { control } \\
\text { UPQC of } \\
\text { three } \\
\text { phases }\end{array}$} \\
\hline & $\mathrm{V}_{\mathrm{a}}$ & 0.00 & $V_{a}$ & 0.00 & $V_{a}$ & 0.00 \\
\hline & $V_{b}$ & 0.00 & $V_{b}$ & 0.00 & $V_{b}$ & 0.00 \\
\hline
\end{tabular}

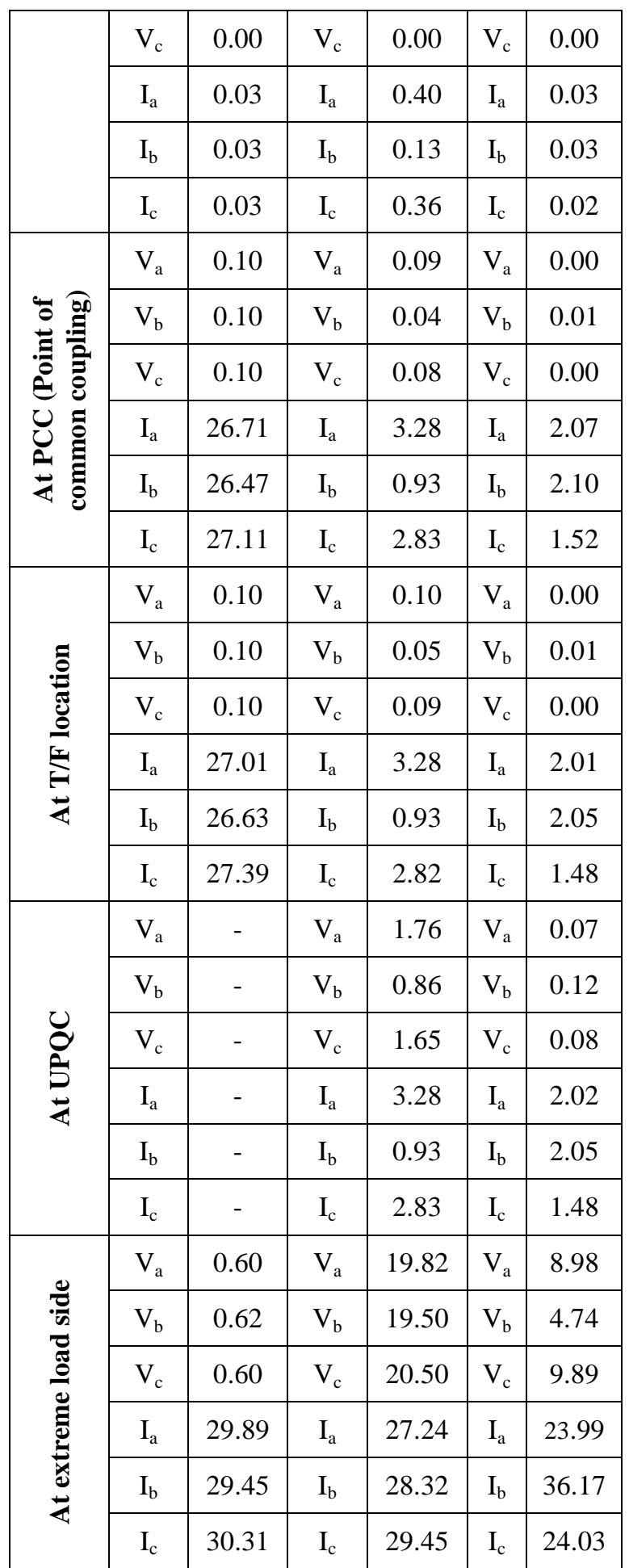

Note: The readings of results marked in red colour are beyond the permissible limit which is 5\% according to IEEE standard. 


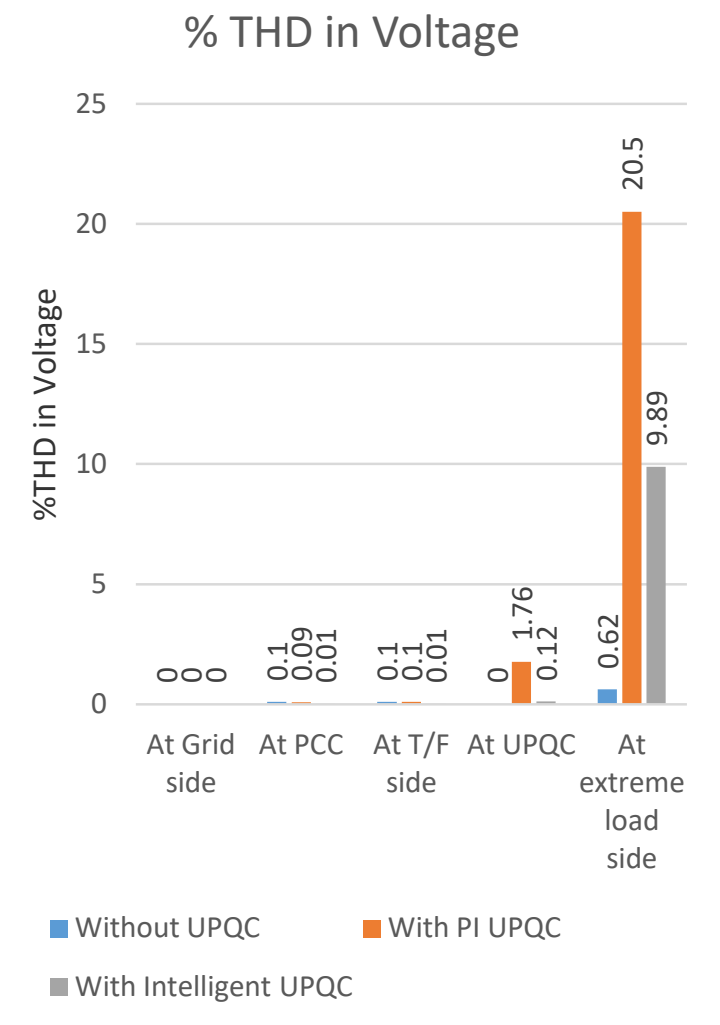

Fig. 8: Comparison table of \%THD in voltage at different locations with and without UPQC

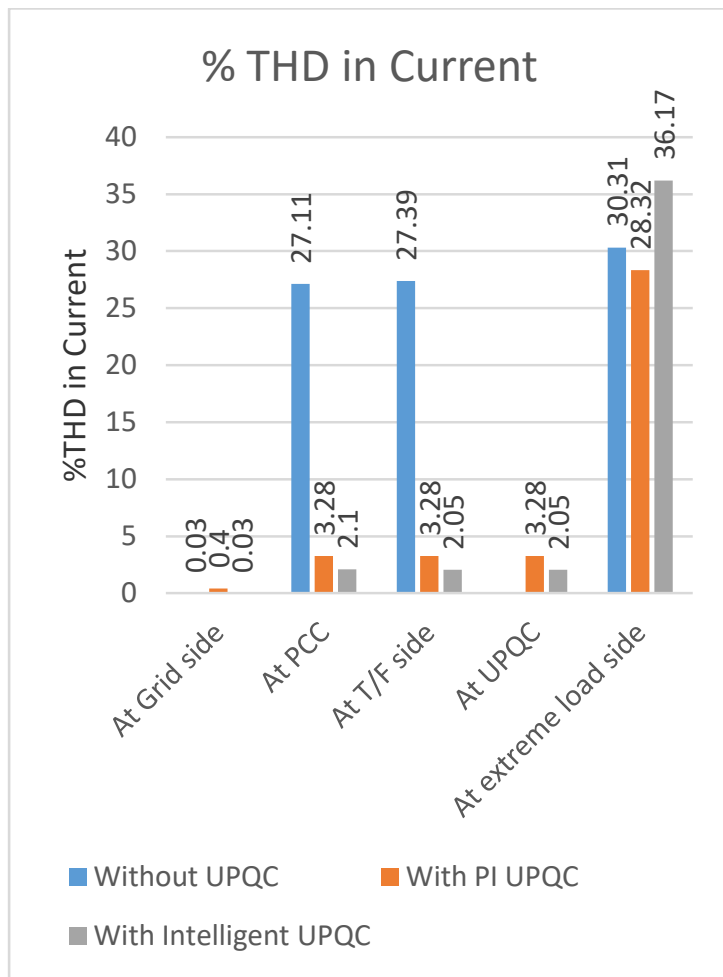

Fig. 9: Comparison table of \%THD in current at different locations with and without UPQC

Note: For comparison \% THD is taken as the maximum value of \%THD among all the three phases

From the above table 1 and figure 9 the following analysis about the \% THD of the power system can be done.

\section{a) At GRID side}

The percentage THD of voltage is zero in all the three cases i.e. without UPQC, with conventional UPQC and intelligent UPQC an in case of current $\%$ THD is more in conventional UPQC and less in other two cases

\section{b) At PCC}

The \%THD in voltage is more without UPQC, less with conventional UPQC and least with intelligent UPQC and in current \%THD is very large without UPQC, less with conventional UPQC and least with intelligent UPQC

\section{c) At T/F side}

The \%THD in voltage without UPQC and with conventional UPQC is more and with intelligent UPQC it is less and in current \%THD is very high without UPQC with conventional UPQC it is less with intelligent UPQC it is further reduced.

\section{d) At UPQC}

The \%THD in voltage with conventional UPQC is more and with intelligent controlled UPQC it is reduced considerably and in current \% THD is more with conventional UPQC which is reduced with intelligent controlled UPQC

\section{e) At extreme load side}

The \% THD in voltage without UPQC is less whereas in case of system with UPQC it is most with PI controlled UPQC. This is because some harmonicas are generated by the UPQC into the extreme load side and in current \%THD without UPQC is maximum with intelligent controlled UPQC for the same reason.

\section{CONCLUSION}

From the above discussion it can be concluded that in the case of voltage the \%THD is well within permissible limits with all the three cases i.e. without UPQC, with conventional UPQC and with intelligent UPQC, but the results shows that the intelligent UPQC has better efficiency than the conventional UPQC and improved performance, at all the places except at the extreme load side where the \%THD is more with intelligent UPQC and most with conventional UPQC, this is because some harmonics are added due to UPQC itself at the extreme load side but it does not propagate through the network.

In the case of current the conventional UPQC and intelligent UPQC have shown significant improvement in the power quality as shown in the graph, the results shown by intelligent controlled UPQC are best in case and are also improved as compared to conventional UPQC. At extreme load side the \% THD is more with intelligent UPQC and 
least with conventional UPQC because of the same reason as in the case of voltage. Overall it can be concluded that the intelligent UPQC has improved performance as compared to the conventional UPQC at most of the locations in the power system.

\section{REFERENCES}

[1] Vinod Khadkikar, Enhancing Electric Power Quality Using UPQC: A Comprehensive Overview, IEEE transactions on power electronics, 2012, vol. 27, no. 5.

[2] V. S. C. Raviraj and P. C. Sen, Comparative study of proportional integral, sliding mode and fuzzy logic controllers for power converters, IEEE Trans. Ind. Appl., vol. 33, no. 2, pp. 518-524, Mar./Apr. 1997.

[3] J. H. Marks and T. C. Green, Predictive control of active filters, Proc. Inst. Elect. Eng. Conf. Power Electronics and Variable Speed Drives, Sep. 2000, pp. 18-23.

[4] Y. Chen, L. F. Sanchez, K. M. Smedley, and G. Chen, One-cycle controlled unified power quality conditioner for load side voltage sag compensation, Proc. Power Electronics Specialists Conf., 2005, vol. 36, pp. 282-288.

[5] Sumeet Singh, Mukul Chanakya, A Review on Power Quality Improvement by UPQC, International Journal of Enhanced Research in Science Technology \& Engineering, ISSN: 2319-7463 Vol. 4 Issue 3, March-2015, pp: (179-184).

[6] Sumeet Singh, Mukul Chanakya, Power Quality Improvement Using UPQC for system with non-linear loads, International Journal of Engineering and Technical Research (IJETR), ISSN: 2321-0869, Volume-3, Issue-6, June 2015.

[7] Vadirajacharya G. Kinhal, Promod Agarwal, and Hari Oam Gupta, Performance Investigation of Neural-Network-Based Unified Power-Quality Conditioner, IEEE transanctions on power delivery. Vol. 26, no. 1 january 2011.

[8] Indranil.Saaki, G.T Chandra Sekhar, U.Salma, B.Shankar Prasad, Multiconverter Unified Power Quality Conditioning System Using Artificial Neural Network Technique, India Conference (INDICON), 2011 Annual IEEE. 